\title{
Desafios da administração pública brasileira: governança, autonomia, neutralidade ${ }^{1}$
}

\author{
Maria das Graças Rua
}

\section{Introdução}

O objetivo deste texto é contribuir para o debate do problema da neutralidade da burocracia versus o requisito da autonomia de decisão, elemento fundamental do modelo de administração pública gerencial.

Este problema assume especial relevância frente aos objetivos de aumentar a governança do Estado e constitui um dos desafios centrais do Plano Diretor da Reforma do Aparelho do Estado, particularmente no que diz respeito à forma de administração do chamado "núcleo estratégico" — responsável pela definição das leis e políticas públicas — e das "atividades exclusivas de Estado" - caracterizadas pelo exercício do poder de legislar e tributar, fiscalizando, regulamentando e transferindo recursos.

Não ambiciono apresentar soluções. Ao contrário: pretendo somente iniciar um levantamento das graves dificuldades que o problema impõe. Para isto, organizei a discussão em quatro seções. Na primeira, apresento rapidamente os conceitos de governabilidade e governança, procurando chamar a atenção para o fato de que a distinção entre eles representa apenas um recurso analítico e argumento que: a) a atividade política está presente em ambos; e b) o modelo de administração pública burocrática exibe contradições não somente devido aos desafios colocados à atividade governamental pelas mudanças do mundo contemporâneo, mas também em razão das clivagens que estabelecem entre racionalidade instrumental e neutralidade burocrática, por um lado, e o exercício da autoridade e da decisão política, por outro.

Na segunda seção, a partir das distinções clássicas de Max Weber entre política e administração, políticos e burocratas, procuro caracterizar a neutralidade burocrática e mostrar que representa, na realidade, apenas

Maria das

Graças é socióloga, doutorada em Ciência Política pelo IUPERJ e professora do Departamento de Relações Internacionais da UnB 
um dos elementos de uma construção típico-ideal, cada vez mais distante de qualquer correspondência com o mundo real. E sustento que, ainda que a neutralidade burocrática fosse realmente possível, cabe indagar pelo menos sobre: a) como torná-la uma característica efetiva e consolidada do comportamento dos agentes da administração pública; e b) quais as suas consequiências sob a ótica dos valores democráticos mais amplos.

Em seguida, comento rapidamente o processo de mudança do modelo de administração pública; e apresento algumas das características do chamado Modelo de Administração Pública Gerencial que, em lugar da neutralidade, implicam elevado grau de autonomia por parte dos agentes burocráticos - em especial a flexibilidade, a descentralização e horizontalização das estruturas e a participação dos atores sociais.

Por fim, apresento algumas considerações finais, procurando mostrar que, da mesma maneira que a neutralidade, a autonomia burocrática apresenta dificuldades e que a proposta da "autonomia imersa" ou "autonomia inserida" exibe implicações que merecem reflexão mais demorada.

\section{Governabilidade, governança e administração pública burocrática}

Dentre os muitos e complexos desafios da reforma do Estado, um vem se destacando pela sua recente inclusão no debate político e acadêmico: a capacidade do sistema político de responder satisfatoriamente às demandas da sociedade e de enfrentar os desafios da eficiência e eficácia da ação pública em contextos de complexidade e incerteza crescente. Nesse sentido, dois diferentes conceitos têm ocupado o centro da discussão, cada um deles referindo-se a uma dimensão do problema.

A primeira refere-se às condições sistêmicas do exercício do poder, e envolve as características do sistema político, a forma de governo, as relações entre os poderes, o sistema partidário, o sistema de intermediação de interesses e outras (DINIZ, 1996). Trata-se da dimensão da governabilidade, cuja discussão remonta à década de 60 (Huntington, 1968; 1975; HABERMAS , 1987; O'CONNOR , 1973)

A outra diz respeito à maneira pela qual o poder é exercido na administração dos recursos econômicos e sociais, tendo em vista o desenvolvimento e envolve os modos de uso da autoridade, expressos mediante os arranjos institucionais que coordenam e regulam as transações dentro e fora dos limites da esfera econômica (MELo, 1996). Trata-se da dimensão da governança, cujo conceito - de formulação bastante recente — pode ser resumido como o conjunto das "condições financeiras e administrativas de um governo para transformar em realidade as decisões que toma" (Bresser Pereira, 1997). 
Esta última dimensão mostra-se particularmente relevante no caso brasileiro, quando se tem em mente as constatações recentes de que, em lugar da suposta paralisia decisória, o que tem se observado é a incapacidade do governo no sentido de implementar as decisões que toma. Dessa forma, à hiperatividade decisória da cúpula governamental contrapõe-se a falência executiva do Estado, que não se mostra capaz de tornar efetivas as medidas que adota e de assegurar a continuidade das políticas formuladas (DinIZ, 1996).

Neste sentido, vale assinalar que, ao contrário do que eventualmente se supõe, refletir sobre os dois conceitos e/ou optar por um deles como elemento de recorte analítico não significa assumir a existência de qualquer disjuntiva entre uma dimensão propriamente política do processo de governo (governabilidade) e uma outra, restrita às rotinas de gerenciamento despolitizado (governança). Uma perspectiva desta natureza é exatamente o que pretendo questionar neste texto, uma vez que sustento, primeiro, que administração é política; e segundo, por implicação, a existência de um vínculo indissolúvel e de uma articulação dinâmica entre governabilidade e governança. Na realidade, a distinção entre as duas significa apenas um recurso de análise.

A governança compreende duas importantes capacidades: a financeira e a administrativa. A primeira refere-se à disponibilidade de recursos para realizar investimentos, assegurar a continuidade das políticas em andamento e introduzir novas políticas públicas. A segunda diz respeito à disponibilidade de quadros executivos, ao estilo de gestão e aos limites impostos à ação administrativa. Neste sentido, Bresser Pereira (1997) assinala que, se nos anos 80 as tentativas de solucionar a crise do Estado privilegiavam as políticas de ajuste fiscal, nos anos 90 os esforços nesse sentido não bastam: é necessário que se combinem consistentemente com a busca da maximização da capacidade gerencial do Estado.

De acordo com o mesmo autor, este último problema resulta de uma contradição intrínseca ao modelo de administração pública vigente no mundo ocidental moderno desde o século XIX: o modelo de administração burocrática:

“...a administração pública burocrática, que Weber descreveu como uma forma de dominação 'racional-legal', trazia embutida uma contradição intrínseca. A administração burocrática é racional, nos termos da racionalidade instrumental, à medida em que adota os meios mais adequados (eficientes) para atingir os fins visados. É, por outro lado, legal, à medida em que define rigidamente os objetivos e os meios para atingi-los na lei. Ora, em um mundo em plena transformação tecnológica e social, é impossível para o administrador ser 
racional sem poder adotar decisões, sem usar de seu julgamento

discricionário, seguindo cegamente os procedimentos previstos em lei”. (Bresser Pereira, 1997:41).

Talvez caiba acrescentar que enquanto a adoção dos "meios mais adequados para atingir os fins visados" supõe escolher entre alternativas previamente estabelecidas e delimitadas pela autoridade legal, a definição dos "objetivos e os meios para atingi-los na lei" remete ao mundo da política, esfera na qual as próprias alternativas são construídas e as decisões são tomadas em resposta a interesses, necessidades e demandas freqüentemente conflituosos.

Neste sentido, ao enfatizar a racionalidade enquanto ação instrumental de adequação entre meios e fins, o modelo de administração burocrática como mecanismo de dominação racional-legal implica uma dicotomia entre administração e política que é, ela própria, contraditória.

Essas considerações remetem a uma das mais instigantes questões acerca da política administrativa e da reforma do Estado: o significado, a desejabilidade e os limites da neutralidade burocrática nas democracias contemporâneas.

\section{Um (entre vários) paradoxos do governo no estado democrático}

Entre os diversos atores que transitam na esfera pública, dois assumem papéis especialmente relevantes e, de certa maneira, mais visíveis: os políticos e os burocratas. ${ }^{2}$

Idealmente, os políticos têm como missão promover o interesse público, isto é, o bem comum, contribuindo para o desenvolvimento da sociedade e o bem-estar geral. Para isto, são investidos de autoridade decisória e supõe-se que venham a exercê-la conforme padrões universalistas. A realidade, entretanto, é bem distinta: o que leva os indivíduos ao exercício da atividade política freqüentemente é o desejo do poder, da glória e da riqueza e a capacidade de usar a autoridade para beneficiar interesses particulares, de grupos específicos, mesmo quando não se trata de vantagens estrita ou diretamente pessoais. Este é um dos paradoxos do governo.

Esta tensão entre o ideal e o mundo real da política, entre o bem público e o interesse particular, tem sido objeto da reflexão política e do esforço de construção de mecanismos institucionais que configuram o que hoje conhecemos como democracia liberal: a regra da maioria, a separação e independência dos poderes, o mandato representativo limitado, as eleições livres e regulares, e outras. 
Embora a discussão desse problema, no que diz respeito aos políticos, remonte ao século XVII, preocupações correspondentes aos burocratas são muito mais recentes, apesar das apreensões manifestadas por autores como Stuart Mill, já no século XIX.

Isto se deve, em parte, ao fato de que a moderna burocracia é muito mais recente do que a moderna classe política, já que o modelo de administração pública burocrática, hoje generalizado nas sociedades ocidentais, só veio substituir o modelo de administração pública patrimonialista no século XIX. Por outro lado, deve-se também ao fato de que o modelo de administração pública burocrática surge, tendo a neutralidade como um dos seus princípios.

De fato, em "Burocracia", Max Weber (1979) indica ser característica do processo de burocratização e da burocracia o cumprimento "objetivo" das tarefas, significando isso, primordialmente, um cumprimento de tarefas a partir do conhecimento técnico especializado e segundo regras calculáveis e "sem relação com pessoas". Este é o princípio do sine ira et studio: um comportamento de tal forma neutro que exclui dos negócios oficiais o amor, o ódio, as preferências, todos os elementos pessoais, irracionais e emocionais, que fogem ao cálculo.

Nas sociedades contemporâneas, Weber constata ser essa a natureza específica da burocracia, louvada como sua virtude especial. E quanto mais complexa e especializada se torna a cultura moderna, tanto mais requer o perito despersonalizado e rigorosamente objetivo, em lugar do mestre das velhas estruturas sociais, que era movido pela simpatia e pelas preferências pessoais, pela graça e gratidão (1979: 250-251).

E em A política como vocação (1979), Max Weber estabelece precisamente a diferença entre políticos e burocratas ao constatar que:

“Tomar uma posição, ser apaixonado - ira et studium — é o elemento do político e, acima de tudo, o elemento do líder político. Sua conduta está sujeita a um princípio de responsabilidade (...) pessoal exclusiva pelo que ele faz (...)" (1979: 116-117).

Já os burocratas se distinguem pela atribuição de executar conscienciosamente as determinações dos políticos, como se resultassem de suas próprias convicções, ainda que lhes pareçam erradas; o compromisso de evitar envolvimento com partidos ou líderes políticos, de modo a constituir-se em instrumentos de qualquer governo legítimo; o dever de atuar como conselheiros desinteressados e imparciais na execução das decisões governamentais. De acordo com Weber, o princípio de responsabilidade que rege a ação do servidor público é exatamente o oposto daquele que caracteriza o político: 
"Sine ira et studio — sem ressentimento nem preconceito -

ele administrará seu cargo. Daí não fazer precisamente o que o político, o líder bem como seu séquito, tem sempre e necessariamente de fazer, ou seja, lutar (...). Sem essa disciplina moral e essa omissão voluntária, no sentido mais elevado, todo o aparato cairia aos pedaços." (1979: 116-117)

Nesses termos, segundo Caiden (1996), o conceito de neutralidade é aparentemente muito simples, baseando-se nos princípios de:

a) separação entre as carreiras políticas e administrativas e

b) de despolitização do serviço público.

Os políticos formulam os fins, decidem e ordenam; os burocratas se encarregam da provisão dos meios e executam as decisões de acordo com as ordens recebidas. Os políticos conquistam seus cargos mediante a competição na arena política, com base na sua competência política, sendo julgados pelos seus pares e pelo eleitorado.

Os burocratas são selecionados mediante sua competência técnica em arena de competição administrativa, sendo julgados pelos seus pares e pelos seus superiores políticos. Os burocratas não se envolvem em atividades político-partidárias, nem expressam publicamente suas opiniões acerca da atividade política ou governamental.

Portanto, administração e política são esferas distintas e separadas a partir da proibição legal de acúmulo ou superposição de funções. A atividade burocrática deve ser regida pelos critérios da expertise, confiabilidade, confidencialidade, impessoalidade, imparcialidade, moralidade, entre outros.

A esta altura, cabem diversas indagações. O que é que autoriza supor que o comportamento burocrático exiba tais características? Por que estariam os burocratas infensos ao paradoxo do governo acima mencionado? Seria a neutralidade burocrática apenas uma construção hipotética, um recurso conceitual? Ou seria efetivamente constatável no mundo das realidades efetivas? Aparentemente tão desejável, quais seriam as conseqüências não antevistas da neutralidade burocrática?

Em primeiro lugar, nada autoriza supor que haja uma "natureza" própria dos agentes burocráticos, capaz de torná-los distintos dos outros homens e de impedir que sejam maximizadores e ambicionem a glória, a riqueza e o poder. Assim sendo, os administradores públicos estariam submetidos ao paradoxo do governo, acima mencionado, da mesma maneira que os políticos.

Na realidade, o próprio modelo de administração burocrática, com a sua ênfase nos controles, processos e rituais surgiu, em grande parte, como tentativa de resolver tal paradoxo, à medida que se destinava a cercear a corrupção, o nepotismo e o clientelismo típicos da administração pública patrimonialista. 
Entretanto, apesar do inegável avanço que representou neste sentido, ainda assim, os controles burocráticos têm se mostrado formalísticos e insuficientes diante das grandes tentações que um poder cada vez mais sólido e abrangente coloca aos que exercem os cargos administrativos.

De fato, no mundo contemporâneo, o poder administrativo é capaz de sustentar ou de destruir instituições. Numa sociedade cada vez mais avançada tecnologicamente, onde a informação representa um recurso de poder inestimável, e onde os meios de execução das decisões são cada vez mais complexos, o destino dos líderes políticos encontra-se intimamente dependente do desempenho dos quadros administrativos. $\mathrm{Na}$ realidade, o equilíbrio de poder vem se alterando consistentemente em benefício dos administradores e em detrimento dos políticos (CAIDEN, 1996: 30).

Contudo, enquanto os políticos são regulamente submetidos à avaliação eleitoral, a burocracia, por definição, não apenas é politicamente irresponsável, como também deve ser protegida das turbulências do jogo político, mantendo-se estável e segura em suas posições através de sucessivas mudanças de governo - já que os quadros administrativos são elementos constitutivos do Estado e não do governo.

Nessas condições, como impedir que os agentes administrativos — da mesma forma como ocorre com os políticos — usem seus recursos de poder e sua autoridade em favor de interesses particulares e em detrimento do bem público?

Este ponto mostra-se tão mais importante quando se tem em mente que, no mundo real da política o próprio processo de representação de interesses não se limita às lideranças políticas e aos políticos autorizados pelo voto. Todavia, existem sérias restrições ao processo burocrático de representação de interesses, pois, conforme coloca Reis:

“(...) discrimina contra interesses não organizados; tende a se limitar ao âmbito de setores funcionais particulares, (...) mostrando-se incapaz de articular interesses intersetoriais; revela um inevitável conservadorismo, (...) porque a agregação de interesses lograda cristaliza a correlação de forças existente." (1989: 103).

Para solucionar o problema, têm sido propostos arranjos como a rotatividade dos cargos, com períodos de curta duração, de modo a evitar a personalização do poder; mecanismos de avaliação interna; comissões externas de avaliação e fiscalização; descentralização das decisões e ações; estabelecimento de instituições rivais que venham a competir pelo poder e cooperar quanto aos fins; processos de treinamento, que incluam a disseminação de normas de comportamento compatíveis com o interesse público; e a criação de mecanismos que tornem a burocracia dotada de responsiveness frente à sociedade, sujeita ao controle social.

O problema tem sido como operacionalizar tais arranjos de maneira eficaz: não existe, para o controle da burocracia, uma engenharia política 
generalizadamente adotada, como aquela estabelecida com relação aos políticos nas democracias liberais.

Assim, o princípio da neutralidade burocrática parece representar apenas um elemento da construção típico-ideal weberiana, muito distante do que se constata no mundo empírico.

De fato, estudos recentes têm mostrado que, diversamente do que pretendia a separação analítica entre política e administração, fica claro que os agentes administrativos não são neutros, mas sim dotados de interesses próprios, que tentam maximizar. Agem como atores políticos, mostrando-se capazes de mobilizar recursos políticos, como informação e apoio de grupos de interesse da sociedade. Além disso, possuem capacidade para desenvolver concepções próprias sobre as políticas governamentais e sobre o seu próprio papel no jogo político, independentemente de considerações de natureza estritamente técnica. Finalmente, são capazes não apenas de competir com os políticos, mas de efetivamente entrar em conflito com eles, visando não somente decisões favoráveis às suas propostas quanto a policies específicas, mas até mesmo disputando o controle do processo político (RUA, 1992; RUA e AGUiar, 1995).

Esses diversos aspectos do comportamento da burocracia têm se manifestado com regularidade em governos de diversos países democráticos, não sendo possível descartar sua importância sob o argumento de que representam distorções características dos regimes autoritários ou das democracias ainda não consolidadas. Essas regularidades chamam a atenção de Peters, que introduz a hipótese do "governo burocrático", compreendida em termos da possibilidade de os agentes burocráticos assumirem o controle do processo governamental, restando aos políticos apenas funções de legitimação das decisões burocráticas (Peters, 1981).

Desta forma, chega-se à última deste primeiro conjunto de questões: seria a neutralidade burocrática um valor absoluto, desejável em si mesmo? Ou implicaria conseqüências que imporiam a discussão acerca da sua desejabilidade ou conveniência? Esta discussão parece conduzir a um dilema.

Sem qualquer sombra de dúvida, os valores implícitos no princípio da neutralidade burocrática são, considerados abstratamente sob a perspectiva ética, extremamente desejáveis. Sob a ótica dos valores democráticos, de todos os matizes, não há como negar a importância do combate ao favoritismo, à patronagem, à venalidade, à discriminação, em favor do profissionalismo, do mérito e da imparcialidade. São esses valores que orientam padrões de conduta destinados a assegurar a previsibilidade essencial à realização dos fins individuais e coletivos sob o império da lei (calculabilidade a partir de normas universais estáveis). 
Entretanto, a experiência histórica tem mostrado que a contrapartida da neutralidade burocrática pode ser a irresponsabilidade política e a ausência de compromisso com valores democráticos. De fato, uma burocracia despolitizada, que se conduz como simples instrumento de execução das ordens dos seus superiores, tanto pode servir à democracia, como pode ser importante recurso para a implantação de regimes ditatoriais e tirânicos, como mostram, entre outras, as experiências ainda recentes do nazismo e das ditaduras latino-americanas.

\section{A mudança do modelo de administração pública}

Na primeira metade da década de 70 iniciou-se uma grande crise econômica de escala mundial, cujo marco inicial mais visível foram as duas grandes crises do petróleo (1973 e 1979). Até então, o mundo capitalista vivia num período de altas taxas de desenvolvimento econômico e de um amplo consenso quanto ao papel do Estado de promover o crescimento econômico e o bem-estar social. No início dos anos 80, encerra-se esta fase de prosperidade vivida desde o fim da Segunda Guerra e inicia-se uma prolongada recessão, cujos efeitos são uma acentuada crise fiscal, acompanhada de uma crise do modo de intervenção do Estado e de uma crise de governabilidade.

Além disso, um processo que vinha se desenvolvendo de maneira acentuada desde a Segunda Guerra - a globalização e as grandes transformações tecnológicas, especialmente nas áreas de microeletrônica e telecomunicações - assume uma dinâmica mais acelerada a partir do fim da década de 80. Com a queda do Muro de Berlim, em 1989, e com a dissolução da União Soviética em 1991-1992 acabam-se as principais distinções políticas e econômicas entre o mundo ocidental, democrático e capitalista e o mundo oriental, autoritário e socialista.

Nesse novo ambiente, aumenta a interdependência das nações, os Estados nacionais passam a dispor de menor capacidade regulatória, tornam-se mais vulneráveis às forças transnacionais (desde as corporações até os investidores individuais, desde os empreendimentos legítimos até o crime organizado), perdem boa parte do seu controle sobre os fluxos financeiros e comerciais e sobre a tarefa de decidir autonomamente as suas políticas macroeconômicas.

Embora a crise econômica e a crise fiscal pudessem ser contornadas com a redefinição do papel do Estado na economia e com o corte de políticas sociais, o mesmo não se aplicava à crise de governabilidade e aos desafios da globalização. Na verdade, não apenas o Estado passou a contar com menos recursos, mas também passou a dispor de menos poder efetivo. Logo, a solução não poderia se limitar à esfera econômica, mas deveria se estender ao modelo político-administrativo. 
De fato, soluções econômicas não seriam suficientes para superar a inflexibilidade da burocracia: seu conservadorismo, sua relutância em se afastar dos precedentes, sua adesão à letra estrita da lei, seu comportamento refratário à inovação e sua generalizada conformidade aos padrões grupais. As mudanças em andamento impunham a presença de quadros criativos, flexíveis e capazes de inovar, competitivos e comprometidos em melhorar o seu desempenho, orientados para a sociedade em lugar de auto-referidos, dotados da motivação resultante da capacidade de acreditar no que estivessem realizando.

É nesse contexto que se iniciam as medidas de modernização do setor público que, por longos e diversos processos de ensaio e erro, acabaram resultando no modelo que se convencionou chamar de administração pública gerencial.

No final da década de 70 e início de 80 constatava-se a existência, nos países anglo-saxônicos, de uma opinião pública desfavorável à burocracia pública e ao mesmo tempo uma inclinação em valorizar o modelo de gestão adotado pelo setor privado. Com a eleição do governo conservador na Grã-Bretanha e republicano nos EUA, iniciou-se a implantação, no setor público, de formas de gestão importadas diretamente do setor privado, nas quais a ênfase recaía sobre o objetivo de cortar custos e aumentar a produtividade, e onde era possível observar a ausência da percepção das diferenças entre a atividade privada e a atividade pública (ABRUCIO, 1996).

Basicamente, apesar dos diversos arranjos adotados em diferentes momentos e em experiências diversas, o modelo gerencial puro, importado diretamente do setor privado, exibia as seguintes características:

a) uma lógica de completa separação entre a esfera da política e a esfera da administração;

b) uma concepção estritamente econômica, baseada na avaliação técnica de custo/benefício;

c) um princípio central: a eficiência, compreendida como eficiência operacional, que implica o aumento da consciência dos custos e requer uma rígida especificação de objetivos e controles;

d) objetivo de produtividade e dinâmica da competição à maneira da concorrência no mercado; e

e) público-alvo concebido como o conjunto dos consumidores, na sua condição de contribuintes.

Pode-se discutir vários ângulos de cada uma dessas características. Entretanto, a fim de não alongar excessivamente o debate, basta apontar que alguns dos seus problemas decorrem, basicamente, do fato de que o modelo gerencial puro é totalmente apolítico - e por isso mostra-se inadequado à administração pública.

Vale observar que a sua lógica de absoluta separação entre política e administração, curiosamente, é a mesma que orienta o modelo de 
administração burocrática, mas também é a mesma que orienta todas as concepções que, por assim dizer, se baseiam na mística do mercado. Para estas, política e mercado devem ser não apenas esferas separadas, mas completamente estanques - e o mercado funcionaria tão melhor quanto menor fosse a ingerência da política. Esta visão totalmente ingênua e equivocada já foi suficientemente discutida e criticada por diversas vertentes do pensamento político. Aqui basta lembrar de que a política surge sempre que há conflito de interesses materiais ou ideais e tal conflito potencialmente se manifesta sempre que há mais de um indivíduo desenvolvendo uma atividade qualquer ou simplesmente existindo (SChMitTer, 1974). ${ }^{3}$

Assim, na segunda metade da década de 80 , importantes mudanças começaram a ser introduzidas, a partir da percepção das diferenças entre a gestão do setor privado e do setor público. As duas principais transformações foram:

a) a priorização dos conceitos de flexibilidade, planejamento estratégico e qualidade, alternando a dinâmica interna das organizações públicas; e

b) a orientação dos serviços públicos para as demandas e anseios dos cidadãos, sem abandonar o conceito empresarial da busca da eficiência (ABRUCIO, 1996).

$\mathrm{Na}$ tentativa de encontrar uma solução que compatibilizasse as vantagens da administração gerencial com as características próprias do setor público, diversas propostas surgiram, dando origem a diferentes modelos. Não cabe aqui discuti-los. Vale apenas mencionar características centrais de alguns deles que, reunidas, compõem o que hoje se entende como modelo de administração pública gerencial e que têm orientado os esforços em direção à reforma administrativa no Brasil:

a) $\mathrm{O}$ foco é o cidadão, e as atividades se orientam para a busca de resultados.

b) O princípio da eficiência econômica cede espaço ao princípio da flexibilidade.

c) Ênfase na criatividade e busca da qualidade;

d) Descentralização, horizontalização das estruturas e organização em redes.

e) Valorização do servidor, multiespecialidade e competição administrada.

f) Participação dos agentes sociais e controle dos resultados.

Diversos destes aspectos contemplam (ou podem contemplar) a dimensão política da administração pública. É o caso princípio da flexibilidade, que implica a tentativa de superar a rigidez burocrática e a orientação primária de maximização custo/benefício e de admitir a 
interação com o ambiente social. O mesmo pode ser dito da descentra-

lização e da horizontalização das estruturas, que implicam autonomia de gestão e tendem a romper com o princípio da hierarquia e com a ética da obediência situados na base da neutralidade e despolitização da burocracia. Por fim, é o caso, especialmente, da participação dos agentes sociais, que implicam as noções de gestão participativa e se baseiam nos conceitos de transparência, accountability, participação política, eqüidade e justiça.

\section{Considerações finais: os dilemas da autonomia burocrática}

Nesse sentido, um conceito fundamental e freqüentemente pouco explicitado é o de autonomia. Em acepção ampla, pode ser entendido como a capacidade de um ator ou agência de formular preferências e executar decisões, sem sofrer constrangimentos decorrentes de relações de subordinação. Vale assinalar que, conforme coloca Bresser Pereira (1997:43), "o conceito de autonomia da burocracia pública não deve ser confundido com o de insulamento burocrático, ou seja, o isolamento das agências estatais em relação às influências políticas", proposto como recurso de separação entre a política e a administração e de despolitização da burocracia, de maneira a protegê-la do populismo econômico e do clientelismo.

Mais precisamente, o conceito de autonomia da burocracia pública pode ser operacionalizado como a capacidade de ocupar posições centrais no governo; de formular preferências políticas; de ajustar os objetivos aos procedimentos já estabelecidos; a disponibilidade de qualificações para comando ou gerenciamento das atividades; e a capacidade de controlar a implementação das decisões públicas (RosE:1974; PETERs: 1987).

Estas capacidades podem se consolidar mediante o arranjo denominado "autonomia imersa" ou "autonomia inserida" proposto por Peter Evans (1995:248), segundo o qual, para que as agências governamentais ganhem eficácia e sejam capazes de realizar transformações, devem estar imersas em uma densa rede de relações sociais que as vinculam aos seus aliados na sociedade a partir de objetivos de mudança. Para o autor esta seria a forma de assegurar a democracia, evitando que a burocracia venha a se tornar governo, em substituição aos políticos.

Esta concepção apresenta diversos problemas. Em primeiro lugar, conquanto a idéia de autonomia governamental não ofereça dificuldades do ponto de vista conceitual, o mesmo não acontece com "autonomia imersa" ou "autonomia inserida". Conforme colocam Tavares de Almeida e Moya (1997:121): 
"Não fica claro o que seja 'autonomia inserida' e no que ela se distinguiria das condições normais de operação dos governos nas democracias antigas e estáveis. A menos que se imagine que o governo não é senão o comitê executivo dos interesses predominantes na sociedade, alguma capacidade de iniciativa autônoma e alguma sustentação político-parlamentar são traços típicos de todo governo democrático que não esteja à beira do colapso."

Eu acrescentaria que não apenas a sustentação político-parlamentar é típica desse tipo e condição de governo, como também o são os vínculos com as diversas coalizões de interesses que se constituem como atores políticos em sociedades minimamente inclusivas.

Entretanto, quanto ao conceito de autonomia de Peters, acrescenta-se o arranjo de Peter Evans, tem-se o que o primeiro destes autores indica serem os pré-requisitos para um governo burocrático. Este é o dilema da autonomia burocrática: para atender aos imperativos da governança numa ordem em transformação, é necessário autonomia. Mas a autonomia - do mesmo modo que a neutralidade, embora por vias transversas — não assegura democracia, nem mesmo a autonomia imersa ou inserida, ao contrário do que pretende Peter Evans.

Além disso, o conceito de autonomia imersa ou inserida tem subjacente o suposto de um conjunto de atores sociais forte e generalizadamente atuantes em busca de resultados da ação pública que satisfaçam seus interesses e demandas. Ou seja, não basta constituir burocracias autônomas: é necessário ter atores sociais envolvidos e mobilizados em torno da consecução de metas públicas.

Pelo menos desde Schumpeter (1978) e, mais tarde, de Olson (1971; 1982), são conhecidas as dificuldades para que isso ocorra. Enquanto o primeiro enfatiza o problema da racionalidade política do cidadão médio, o segundo não deixa dúvidas quanto às dificuldades da ação coletiva os elevados custos de organização e coordenação vis-à-vis, o caráter indivisível e não excludente dos bens públicos — nem quanto às nefastas consequiências da hipertrofia dos pequenos grupos (OLSON, 1982 ).

Na verdade, é possível sugerir que a resposta (mas não a solução) ao problema de Olson encontra-se em Michels: a provisão de bens públicos para os grandes grupos — inclusive o controle social — só ocorre efetivamente mediante a ação do empresário político — figura não necessariamente restrita aos políticos dotados de mandato eletivo. Em que medida isto seria diferente dos modelos tradicionais de atuação dos agentes públicos, não somente os políticos, mas também os burocratas?

Ademais, supondo que sejam resolvidos os desafios da ação coletiva e haja organização dos atores sociais, coloca-se ainda, conforme mostra Michels (1982), o problema da oligarquização das organizações 
democráticas (não apenas partidos políticos, mas também associações, sindicatos, conselhos comunitários e setoriais, etc): em que medida as entidades organizadas da sociedade civil são, de fato, representantes dos cidadãos enquanto usuários dos bens públicos?

Se a proposta da autonomia imersa se destina a resolver o problema da vinculação entre a administração pública e a sociedade de maneira a obter agilidade e eficácia, sem perda do controle democrático, uma questão central a ser enfrentada é a de como tornar generalizada e efetiva a participação dos atores sociais.

Desta forma, a autonomia imersa pode levar a uma situação de fortalecimento dos laços dos agentes/agências burocráticas com clientelas específicas, impondo dificuldades à construção de consensos e estabelecendo novos padrões de favorecimento político, em lugar da universalização das relações de cidadania. Por outro lado, pode representar um novo patamar no fortalecimento dos atores burocráticos, em prejuízo dos políticos, quando é possível pensar que é a competição entre os dois tipos de atores - e não a assimetria e subordinação entre eles — que favorece a democracia (ReIs, 1989).

Assim, conforme procuro chamar a atenção em um outro artigo (RUA, 1997), Max Weber ensina que o grande drama da dominação moderna situa-se no campo das relações entre os dominadores: os políticos e a burocracia. Particular destaque teria, na dinâmica dessas relações, a distinção entre as éticas e os tipos de racionalidade característicos de cada um desses atores. Enquanto a burocracia seria orientada pela ética da obediência e pela racionalidade formal, sendo a competência técnica e o mérito as fontes da legitimidade burocrática, os políticos teriam como traços predominantes a ética da responsabilidade e a racionalidade substantiva, fundamentos da legitimidade política.

O efetivo dilema a ser enfrentado pelas democracias seria considerado o inexorável processo de complexificação e burocratização da sociedade moderna e dadas as características de cada um dos agentes do jogo político e os seus recursos de poder, como impedir que a burocracia venha a usurpar o poder e como assegurar que permaneça, sendo apenas um elo de ligação entre dominadores e dominados? Para Weber, a incapacidade de solucionar este problema estaria na base do declínio dos grandes impérios da história (WEBER: 1993). Isto, certamente, não pode ser esquecido quando do debate da autonomia burocrática, especialmente da autonomia imersa.

Finalmente, se este debate sugere que o exercício da autonomia burocrática implica a rejeição do princípio da neutralidade, deve ficar claro que isto significa descartar ambas as suas facetas: não somente a indiferença descompromissada, mas também o universalismo. Quais as conseqüências disso sobre a governabilidade e a governança democráticas? 
Quanto mais presentes se tornarem esses dilemas, maior será a relevância da discussão acerca das relações entre governança, neutralidade burocrática e autonomia para a reforma do Estado e da administração pública, onde o que está em jogo, em última instância, é a democracia enquanto valor maior. 
1 Agradeço a Evelyn Levy por ter me chamado a atenção para a relevância desta temática no âmbito da reforma administrativa brasileira. Este artigo representa uma versão mais elaborada de um outro que apresentei na Semana Max Weber, UnB, setembro de 1997.

2 Considero políticos aqueles cujas carreiras se baseiam no exercício do mandato político. E burocratas, em geral, aqueles cujas carreiras estão orientadas para o exercício de atividades administrativas, com base no conhecimento técnico especializado. Nesse sentido, existem diversos outros atores públicos, como os magistrados e os militares, por exemplo, cujos papéis e lógica de comportamento exibem efetivas distinções com relação aos políticos e aos burocratas propriamente ditos.

3 Pessoalmente, considero a definição do conceito de política proposto por Schmitter demasiado amplo e, portanto, pouco operacional. Em outros textos tenho sugerido que a política consiste no conjunto de instituições e processos destinados à solução pacífica dos conflitos em torno de bens públicos. Acrescento que mesmo esta definição que proponho, é questionada por todos aqueles que compartilham os pressupostos da escola realista das relações internacionais, para a qual a "solução pacífica dos conflitos" exclui a guerra, que é considerada "a continuação da política por outros meios". 


\section{Referências bibliográficas}

ABRUCIO, Fernando Luiz. "O impacto do modelo gerencial na administração püblica: um breve estudo sobre a experiência internacional recente". Brasília: ENAP (mimeo), 1996.

Bresser Pereira, Luiz C. "A reforma do Estado nos anos 90: lógica e mecanismos de controle", Cadernos do MARE, no1, 1997.

CAIDEN, Gerald E. "The concept of neutrality". In H.K. Asmerom and Elisa P. Reis (Orgs.). Democratization and bureaucratic neutrality. New York: St. Martin's Press, INC. ; London: MacMillan Press Ltd, 1996.

DinIz, Eli. "Governabilidade, 'governance' e reforma do Estado: considerações sobre o novo paradigma", XX Encontro Anual da ANPOCS, Caxambu (MG), 1996.

Evans, Peter. Embedded Autonomy. Princeton: Princeton University Press, 1995.

Habermas, J. "Problemas de Legitimación en el Capitalismo Avanzado" In T. MacCarthy (ed.), La Teoria Critica. Madrid: Editorial Tecnos, 1987.

Huntington, Samuel P. Political order in changing societies. New Haven and London: Yale University Press, 1968.

The crisis of democracy. New York: New York University Press, 1975.

Melo, Marcus André. "Governance e reforma do Estado: o paradigma agente X principal”, Revista do Serviço Público, Ano 47, Vol. 120, n. 1, jan-abr, 1996.

Michels, Robert. Sociologia dos Partidos Políticos. Brasília: Ed. UnB, 1982.

OLson JR., M. The logic of collective action: public goods and the theory of groups. Cambridge: Harvard University Press, 1971.

The rise and decline of nations: economic growth, stagflation and social rigidities. Yale University Press, 1982.

O'Connor, J. The fiscal crisis of the State. New York: St. Martin Press, 1973.

Peters, G. B. "The "Problem of bureaucratic government". In: Journal of Politics, vol. 43, No. 1, Feb, 1981.

"Politicians and Bureaucrats in the Politics os Policy-Making". In: Jan Erik Lane (Ed.) Bureaucracy and Public Choice. Beverly Hills: Sage, 1987.

Reıs, Elisa P. "Política e Políticas Públicas na Transição Democrática". In: Alexandrina S. de Moura (Org.), O Estado e as Políticas Públicas na transição Democrática. São Paulo: Vértice; Recife: Fundação Joaquim Nabuco, 1989.

Rose, R. The Problem of Party Government. London: Macmillam, 1974.

RuA, M. das Graças "Políticos e Burocratas no Processo de Policy-Making: A Política de Terras no Brasil, 1945-1984”. Rio de Janeiro: IUPERJ, 1992.

e Aguiar, Alessandra T. "A Política Industrial no Brasil, 1985-1992:

Políticos, Burocratas e Interesses Organizados no Processo de Policy-Making.”, Planejamento e Políticas Públicas, No. 12, dezembro de 1995.

. "Democratization, Unionism and Neutrality of Public Bureaucracy in Brazil: The Case of Bank of Brazil". In: H.K. Asmerom and Elisa P. Reis (Orgs.), Democratization and Bureaucratic Neutrality. New York: St. Martin's Press, INC. ; London: MacMillan Press Ltd, 1996.

. "Novas questões ou antigas preocupações? A Burocracia na sociedade democrática do Final do Século XX". In: Antônio. A. Cançado Trindade e Marcus F. de Castro (Orgs.) A sociedade democrática no final do século. Brasília: Paralelo 15, 1997. 
Schmitter, P. C. "Reflexões sobre o Conceito de Política". Brasília: Ed. UnB, 1974.

SChumpeter, J. Capitalismo, Socialismo, Democracia. Rio de Janeiro: Zahar, 1978.

Tavares de Almeida, M. Hermínia e Moya, Maurício. "A Reforma negociada: O Congresso e a Política e Privatização". Revista Brasileira de Ciências Sociais, v.12, n. 34, junho, 1997.

Weber, Max. "Burocracia”; “A Política como Vocação”; In: H.H. Gerth e C.Wright Mills (Orgs.) Ensaios de Sociologia. Rio de Janeiro: Zahar, 1979.

. Parlamento e Governo na Alemanha Reordenada: Crítica da Burocracia e da Natureza dos Partidos. Petrópolis: Vozes, 1993. 


\section{Desafios da administração pública brasileira: governança, autonomia, neutralidade Maria das Graças Rua}

O objetivo deste texto é iniciar um levantamento da dificuldades impostas à reforma administrativa a partir da consideração do problema da neutralidade da burocracia versus o requisito da autonomia de decisão, elemento fundamental do Modelo de Administração Pública Gerencial. Tal problema assume especial relevância frente aos objetivos de aumentar a governança do Estado e constitui um dos desafios centrais do Plano Diretor da Reforma do Aparelho do Estado, particularmente no que diz respeito à forma de administração do chamado "núcleo estratégico" — responsável pela definição das leis e políticas públicas - e das "atividades exclusivas de Estado" - caracterizadas pelo exercício do poder de legislar e tributar, fiscalizando, regulamentando e transferindo recursos. Para isso, a discussão está organizada em quatro seções. Na primeira, são rapidamente apresentados os conceitos de governabilidade e governança, com ênfase no fato de que a distinção entre eles representa apenas um recurso analítico.

Na segunda seção, a partir das distinções clássicas de Max Weber entre política e administração, políticos e burocratas, busca-se caracterizar a neutralidade burocrática e mostrar que representa, na realidade, apenas um dos elementos de uma construção típicoideal, cada vez mais distante de qualquer correspondência com o mundo real.

Em seguida, comenta-se rapidamente o processo de mudança do modelo de administração pública; e são apresentadas algumas das características do chamado Modelo de Administração Pública Gerencial que, em lugar da neutralidade, implicam elevado grau de autonomia por parte dos agentes burocráticos.

Por fim, são tecidas algumas considerações, procurando mostrar que, da mesma maneira que a neutralidade, a autonomia burocrática apresenta dificuldades e que a proposta da "autonomia imersa" ou "autonomia inserida" exibe implicações que merecem reflexão mais demorada.

\section{Desafíos de la administración pública brasileña: gobernación, autonomía, neutralidad}

Maria das Graças Rua

El objetivo de este texto es iniciar un inventario de las dificultades impuestas a la reforma administrativa a partir de la consideración del problema de la neutralidad de la burocracia versus el requisito de la autonomía de decisión, elemento fundamental del Modelo de Administración Pública Gerencial. Tal problema asume especial relevancia ante los objetivos de aumentar la gobernación del Estado, y constituye uno de los retos centrales del Plan Director de la Reforma del Aparato del Estado, particularmente en lo que se refiere a la forma de administración del llamado "núcleo estratégico" - responsable de la definición de las leyes y políticas públicas - y de las "actividades exclusivas del Estado"- caracterizadas por el ejercicio del poder de legislar y tributar, fiscalizando, reglamentando y transfiriendo recursos. Para ello, la discusión está organizada en cuatro secciones. En la primera se presentan repetidamente los conceptos de gobernabilidad y gobernación, con énfasis en el hecho de que la distinción entre ellos representa solamente un recurso analítico.

En la segunda sección, a partir de las distinciones clásicas de Max Weber entre política y administración, políticos y burócratas, se trata de caracterizar la neutralidad burocrática y mostrar que representan, en realidad, solamente uno de los elementos de una construcción típica-ideal, cada vez más distante de cualquier correspondencia con el mundo real.
Ano 48

Número 3

Set-Dez, 1997

Maria das

Graças é

socióloga, doutorada em Ciência Política pelo IUPERJ e professora do Departamento de Relações Internacionais da UnB 
En seguida, se comenta rápidamente el proceso de cambio del modelo de administración pública, y se presentan algunas de las características del llamado Modelo de Administración Pública Gerencial que, en lugar de la neutralidad, implican un elevado grado de autonomía por parte de los agentes burocráticos.

Por último, se elaboran algunas consideraciones, tratando de mostrar que, de la misma forma que la neutralidad, la autonomía burocrática presenta dificultades, y que la propuesta de la "autonomía inmersa" o "autonomía insertada" exhibe implicaciones que merecen una reflexión más detenida.

\section{Challenges facing the brazilian public administration: governance, autonomy and neutrality}

Maria das Graças Rua

The purpose of this article is to start a survey of the difficulties facing administrative reform in view of the problem of neutrality of the bureaucracy as opposed to the requirement for autonomy in decison-making, a key element in the Managerial Model of Public Administration. This problems becomes particularly relevant given the objective to increase State governance and constitutes one of the major challenges in the Sate Reform Master Plan, particularly with regard to the so called "strategic core", which is responsible for establishing laws and public policies as well as those "activities exclusive to the State", characterized by the exercise of the power to legislate and tax, inspect, regulate and transfer resources. The article has been organized in four sections. In the first, the concepts of governability and governance are briefly introduced, with special emphasis placed on the fact that a distinction between them merely serves an analysis purpose.

In the second section, based on classical distinctions by Max Weber between politics and administration, politicians and bureaucrats, the article seeks to characterize bureauratic neutrality and to show that, in fact, it represents only one of the elements in a typically ideal construction, increasingly distant from the real world.

The article then briefly discusses the change process in the model of public administration and some of the characteristics of the so called Managerial Model of Public Administration are described; these, instead of neutrality, involve a high degree of autonomy on the part of bureaucracy agents.

In conclusion, the article seeks to evince that, just as in the case of neutrality, bureacratic autonomy involves certain difficulties and that the proposal for an "embedded autonomy" or "inserted autonomy" has implications that require a more careful study. 